\title{
-lA Ekinin Farklı Bir İşlevi Üzerine
}

\section{On a Different Function of the Suffix -lA}

\author{
Dr. Öğr. Üyesi Sevda ÖZEN ERATALAY (iD) 1 , Arş. Gör. Şahin YILDIZ (iD) 2
}

\begin{abstract}
$\ddot{\mathbf{O} z}$
Canlı bir varlık olan dil sürekli olarak bir değişime uğrar. Dildeki değişim hem yazı hem de konuşma dilinde hissedilebilir. Bu değişim bir dili bulunduğu konumdan çok farklı bir yere getirebilir. Buna bağlı olarak dilde değişen yapıları saptamak amacıyla birçok araştırma yapılmıştır. Bu çalışmada isimden fiil yapma eki olarak bilinen "-lA-" üzerinde durulacaktır. Eklendiği yapıların anlamlarını derinden etkilemeyip bazen sadece anlamın pekişmesine yardımcı olan ya da bir işin sürekli yapıldığını gösteren bu ek, kaynak olarak gösterilen ya da okutulan hemen her eserde isimden fiil yapma ekleri arasinda gösterilmektedir. Oysa Türkçenin bazı dönemlerinde ekin, fiilden fiil yapma eki olarak da kullanıldığına dair örnekler bulunmaktadır. Eğer dil bilgisel bağlamda yeni bir kural oluşturulacaksa, belirlenen dilin dönemleri içerisinde bu kurala uygun örneklerin saptanması gerekir. Bulunan örnekler hatırı sayılır dereceye ulaştığında bilinen kuralla ilgili yeni şeyler söylenmeli ve bilinen mutlak gerçek değiştirilmelidir. Bu bağlamda çalışmada "-lA-" ekinin bilinen işlevinden ziyade farklı bir işlevi daha ortaya çıkarılmış ve bununla ilgili örnekler tespit edilerek gerekli açıklamalar yapılmıştır. Ekin, Türkçenin çağdaş ve tarihî lehçelerindeki örnekleri, Türkiye Türkçesindeki kullanımları tespit edilmeye çalışılmışıır. Çalışmanın, eklere farklı bir bakış açısı kazandırmak ve Türkçenin zenginliğini ortaya çıkarmak açısından katkı sağlayacağı düşünülmektedir.
\end{abstract}

Anahtar Kelimeler: Türkçe, gramer, yapım ekleri, fiil yapımı, -1A-

Makale Türü: Araştırma

\begin{abstract}
Language, as a living being, is constantly changing. Change in language can be felt both in written and spoken language. This change can make a language very different from where it is located. Accordingly, many studies have been carried out to determine the structures that change in the language. This study will focus on "-1A-, known as the suffix that makes verb from the noun. This suffix, which does not deeply affect the meaning of the structures to which it is added, but sometimes only helps to consolidate the meaning or shows that a work is done all the time, is explained as the suffix that makes verb from the noun in almost every work that is cited or taught as a resource. However, in some periods of Turkish, there are some examples that the suffix is used to make verb from the verb. If a new rule is to be established in the grammatical context, samples appropriate to this rule should be determined within the periods of the specified language. When the examples found reach a considerable degree, new things should be said about the known rule and the known absolute truth should be changed. For this reason, in the study, a function of the suffix -1A different from the known function was revealed and related examples were identified, and necessary explanations were made. The appearances of the suffix in contemporary and historical dialects of Turkish, and its uses in Turkey Turkish were tried to determine. It is thought that the study will contribute in order to gain a different perspective to suffixes and to reveal the richness of Turkish.
\end{abstract}

Keywords: Turkish, grammar, derivational suffixes, verb making -lA-

Paper Type: Research

\footnotetext{
${ }^{1}$ Van Yüzüncü Y1l Üniversitesi, Edebiyat Fakültesi, sevdaeratalay@hotmail.com.

${ }^{2}$ Van Yüzüncü Y1l Üniversitesi, Edebiyat Fakültesi, shnyildiz47@gmail.com.
}

Atıf için (to cite): Özen Eratalay, S. ve Yıldız, Ş. (2020). -1A ekinin farklı bir işlevi üzerine. Afyon Kocatepe Üniversitesi Sosyal Bilimler Dergisi, 22(3), 706-713. 


\section{Giriş}

Değişim ve dönüşüm temelinde farklılaşan diller her zaman bu evrimleşme sürecini takip ederler. Değişen, gelişen ya da dönüşen bir dilin güçlü yapıları kendini korurken, güçsüz yapıların da yavaşça ortadan kaybolduğu görülür. Bununla ilgili Saussure; dilde mutlak bir durağanlığın olmadığını ve dilin tüm bölümlerinin değişebileceğinden söz eder. Bu değişme sürecini evrim olarak nitelendiren Saussure'e göre dilin değişim ve gelişim süresi de değiş̧kendir. Bu değişkenlik içerisinde dilin var olan ilkesi asla değişmez. Dil ırmağının asla kesintiye uğramayacağını ve her zaman akacağını belirten Saussure, bu akıntının hızını da ikincil nitelik olarak değerlendirir (2001, s. 201). Bu bağlamda "dil her zaman değişebilir; ancak bu değişkenliğin belli bir hızı yoktur" anlayışına sahip olabiliriz. Ancak bu değişkenlik içerisinde bile dilin belli başlı kuralları kendini korumaktadır.

Türk dili, ilk yazılı belgeleri olan Göktürk Yazıtlarından günümüze kadar bazı değişikliklere uğramıştır. $\mathrm{Bu}$ uzun süreçte pek çok etken dilin farklılaşmasına zemin hazırlamıştır. Göçebe toplumun yerleşik hayata geçmesi bile başlı başına pek çok değişikliği beraberinde getirir. Bu değişikliklere; savaş, ekonomik etkenler, komşu devlet ya da milletlerle ilişkiler, teknolojik gelişmeler, kitlesel göçler gibi olgular eklenince kültürel dokunun yanı sıra dil ve bu bağlamda o toplumu oluşturan hemen her yapının derinden etkilenmesi kaçınılmazdır. Bir milletin en temel varlıklarından biri olan dil, o milletin yaşadığı olaylara, yaşam şekline, kültürüne ve pek çok sebebe bağlı olarak değişip dönüşebilir. Dildeki bu değişim/dönüşüm dilin hemen her alanında kendini gösterebilir. Dil kendine özgü kuralları değiştirmekte zorlanır; ancak sözcük ya da bazı yapılar bağlamında değişiklikleri bazen olduğu gibi kabul eder, bazen de kendi bünyesine uydurur. Bununla ilgili Johanson'un bazı fikirleri bulunmaktadır. O'na göre dil kendi sınırları içerisinde diğer dillerden etkilenebilir ve o dillerin bazı yapılarını kopyalayabilir. Kolay ve erken kopyalananlar etkilenen dilin en üstünde yerini alırken zor ve daha geç kopyalananlar da en dipte yerini alır (2014, s. 50). Johanson'un bu fikrinden hareketle; bir dilin kendisine ve bağlı bulunduğu dil ailesine özgü belirgin özellikleri daha geç ve zor değişirken, dünyanın diğer dilleri ile ortak olan özellikleri değişime daha elverişlidir. Örneğin, Türkçenin cümle yapısı veya eklemeli oluşu ona özgü bir özelliktir ve bu özelliğinin değişmesi/dönüşmesi oldukça güçtür. Ancak Türkçenin diğer dillerden sözcük alması ya da bazı ekleri bünyesine katması daha olağandır. Buna göre Türkçenin bazı dillerden sözcük alması ya da farklı dillere sözcük vermesi, dilin dayanıklılık göstergesinde oldukça kolaydır. Ama Türkçenin dilbilgisel bağlamda değişikliğe gitmesi onun sözcük alışverişinden daha zor olmaktadir.

Türkçe oldukça gelişmiş bir ek sistemine sahiptir. Ancak Johanson'un da belirttiği gibi Türkçedeki bazı yapılar diğer dillerden geçmiş ya da kopyalanmıştır. Örneğin bugün Türkiye Türkçesinde kullanılan "baharat" ya da "hayvanat" sözcüklerindeki +at eki Türkçe değildir ve çoğul ekidir. Ancak Türkçe bu eki olduğu gibi bünyesinde eritmiş hatta "baharat" sözcüğündeki çokluk ekine +lar çokluk ekini de ekleyerek kullanımını sürdürmüştür. Bu ve bunun gibi örneklere Türkçede pek de rastlanmaz. Çünkü Türkçe kendi bünyesine yabancı ek alma bağlamında sözcük alma bağlamından daha sert yaklaşmaktadır. Yani Türkçede yabancı yapılardan çok yabancı sözcükleri görmek daha mümkün olmaktadır. Sondan eklemeli dil olan Türkçede örneğin, biç̧are gibi olumsuz ön eklerin kullanıldığı yabancı yapılara da rastlanılır. Bu Türkçenin kendine özgü yapısına oldukça ters bir kuraldır; ancak yine de bu yapıyı bünyesinde eritebilmiştir. Bu yapılar ya da bu bağlamlı örnekler oldukça sınırlıdır. Ancak Türkçe yabancı sözcük alma ya da kopyalama noktasında oldukça başarılıdır. Bu, belki de kimilerine göre başarı olarak nitelendirilebilecek bir durum değildir. Ancak Türkçe, yabancı bir sözcüğü kendi bünyesine alırken bu sözcüklerin çoğunu kendi kurallarına uydurma ve Türkçeleştirme yöntemini kullanır. Bu da Türkçenin zenginliklerinden biridir; bu sebepten yabancı bir sözcüğü Türkçeleştirme eğilimi belki de Türkçenin önemli özellikleri arasında sayılmalıdır. Burada konu ile ilgili daha fazla söz söylenebilir; ancak bu, kapsamlı ve daha farklı bir incelemenin konusunu teşkil ettiğinden sadece özet geçmek yerinde olacaktır. 
Türkçenin olmazsa olmaz kuralları vardır ve bu kurallar -sondan eklemeli bir dil olması ya da ünlü uyumunun bulunması- Türkçenin kendine özgü yapısı ile ilgilidir. Bazen bu kurallar bile bazı sebeplerden ötürü farklılıklar gösterebilir. Bu, dilin gelişmesi ya da dönüşmesi bağlamında olağan bir durum olarak değerlendirilebilir. Bundan daha farklı bir konu daha var ki o da Türkçenin kuralları içerisinde hep aynı bağlamda değerlendirilen ve şimdiye kadar yazılmış çoğu dilbilgisi kitabında isimden fiil yapma ekleri arasında gösterilen -1A- çalışmanın konusunu oluşturmaktadır.

Çalışmada yukarıda da bahsedildiği üzere, çok işlek gibi görünmeyen ancak örneklerine oldukça rastlanılan fiilden fiil yapım eki -lA- üzerinde durulacaktır. Eski Türkçeden günümüze daha çok isimden fiil yapma eki olarak gösterilen ve sadece birkaç örnekte fiilden fiil yapma eki olduğu üzerinde durulan bu ek, pek çok dilbilgisi kitabında fiilden fiil yapma başlı̆̆ değerlendirilmeyip isimden fiil yapma ekleri arasında gösterilmektedir (bk. Banguoğlu, 2015; Ergin, 2013; Korkmaz, 2014). Oysa Göktürk yazıtlarından günümüze, tarihî Türk lehçelerinden, Türkiye Türkçesi ağızlarına kadar Türk dilinin hemen her dönemde -lA- ekinin fiilden fiil yapma görevinde kullanılan örneklerine de rastlanılmaktadır. Çalışmayla ekin şimdiye kadar bilinen görevinden başka bir görevi olduğu saptanarak bu ekin, Türkçenin hangi döneminde nasıl karşımıza çıktığı üzerinde durulacak ve örneklerle konu açıklanmaya çalışılacaktır. Elde edilen veriler neticesinde belki de pek çok Türk dili araştırmacısı bundan sonraki çalışmalarında ya da şimdiye kadar yazılan Türk dilbilgisi kitaplarında ek olarak, hem bilinen görevi hem de elde ettiğimiz fiilden fiil yapma görevi alt başlıklarında değerlendirmeye alınacaktır.

\section{Amaç}

Türkçe ile ilgili yapılmış çalışmaların birçoğunda sadece isimden fiil yapım ekleri arasında gösterilen -1A- ekinin, fiilden fiil yapma işlevinde de kullanıldığını örnekleriyle birlikte ortaya koymaktır.

\section{Yöntem}

Çalışmada tarihî Türk yazı dilleri, çağdaş Türk yazı dilleri, Türkiye Türkçesi ve Türkiye Türkçesi ağızları ile ilgili metinler ve bunlarla ilgili yapılan çalışmalar taranmış olup -lAekinin fiilden fiil yapım eki göreviyle kullanıldığı örnekler tespit edilmiştir.

\section{Bulgular}

\subsection{Tarihî Türk Yazı Dillerinde -lA- Eki}

Türk dilbilgisi üzerine yapılan çalışmaları genel olarak, eksiksiz ve doğru biçimde değerlendirebilmek için Türk dilinin tüm dönemlerini göz önünde bulundurmak gerekmektedir. Çünkü Türk dilinin bütün olarak ele almak ve hemen her dönemini iyi bilmek günümüz Türkçesini de iyi anlamak demektir. Örneğin çalışma konumuz olan -1A- eki Eski Türkçede fiilden fiil yapım görevinde kullanılmış olup bu görev bağlamında Türk dilinin dönemleri içerisinde birçok yerde karşımıza çıkmaktadır. Tekin, Orhon Türkçesi Grameri'nde eylemden eylem türeten ekler başlı̆g 1 altında verdiği ekin sıklık çatısı eki olduğunu belirtmiş olup *kunmak 'çalmak' ve bu bağlamda da kunlamakı 'sürekli çalmak, yağmalamak' olarak vermiştir (2016, s. 91). Kunmakın Uygur Türkçesinin önemli eserlerinden olan Altın Yaruk'ta da 'çalmak', edig tavarıg kuntum, altım, ogurladım 'malı mülkü çaldım, aldım, çaldım' biçiminde kullanıldığ1 görülmektedir (Kaya, 1994, s. 120). Yine ekin farklı örneklerde aynı yap1 bağlamında karşımıza çıktığı görülür. Örneğin kolumak 'ant içmek' olarak belirtilen eylemin kolulamak şeklinde de kullanıldığı bilinmektedir (Eraslan, 2012, s. 582). Ayrıca tınmak 'dinlenmek' olarak gösterilen yapının aynı anlamda tınlamak 'dinlenmek' biçiminde -la- eki ile tekrar kullanıldığı gözlemlenir. Pekiştirme görevi olan bu ekin örneklerde de görüldüğü üzere anlam değişikliğine yol açmadığı tam tersine anlamını koruduğu görülmektedir. Tinlamak" eyleminin 'nefes, can ve ruh' anlamlarına gelen tından geldiği söylense de eylemin pek çok eserde tınmak biçiminde 'dinlenmek, derin nefes almak, solumak' (Gabain, 2007, s. 299; 
Paçacıoğlu, 2016, s. 627; Üşenmez, 2010, s. 287) anlamlarında karşımıza çıktığı görülür. Ekin fiilden fiil yapım eki olarak kullanıldığı diğer örneklere değinmek gerekirse; Caferoğlu'nun, Eski Uygur Türkçesi Sözlüğü'nde yarumak'1 'parlamak, 1şıklanmak, aydınlanmak' tanımıyla verdiği görülür. Aynı şekilde yarutmak'ı da 'parlatmak, aydınlatmak ve görünmek' olarak belirtir (1968, s. 288). Bu bağlamda Şinasi Tekin Eski Uygur Türkçesi eserlerinden olan Maytrısimit'te yartalamak'ın 'parıldamak' (1976, s. 505) anlamına geldiğinden söz eder. Örneklerden hareketle ek bir kez daha bize fiilden fiil yapım eklerinden olduğunu hatırlatmaktadır. Yine, Göktürk (Gabain, 2007, s. 300; Tekin, 2016, s. 311) ve Uygur (Caferoğlu, 1968, s. 244) Türkçesi dönemlerinde karşımıza çıkan bir başka fiil de tokumak/tokımak fiilidir. 'Vurmak, dövmek, tokmaklamak, dokumak, yontmak' anlamlarına gelen fiilin bugün Türkiye Türkçesi ağızlarında 'ham ipliği tokaçla dövmek' anlamında tokulamak olarak karşımıza çıktığı görülmektedir (DS, 2009, s. 3952).

Orta Türkçe döneminde de ekin fiilden fiil yapım eki işleviyle kullanıldığına dair örnekler tespit edilmiştir. Dîvânu Lugâti't-Türk'te 'sandığa koymak' anlamına gelen kamak'in kalamak (Ercilasun \& Akkouyunlu, 2015, s. 673) biçiminde aynı anlamda kullanıldığ 1 da görülmektedir. Yine Dîvânu Lûgâti't-Türk'te 'sarmak ve sık1 bağlamak' anlamlarına gelen çoğmak'ın çoğlamak şeklinde 'bohçalamak' anlamına geldiği belirtilmektedir (Atalay, 1999, s. 155-156).

Hacıeminoğlu, -lA- ekinin -ala-/-ele- ile birleştirilemeyeceğini savunarak bazı örneklerin -a- ile genişlememiş tabanlarında görüldügünü söyler. Buradan hareketle Hac1eminoğlu, düğmek'ten düğlenmek 'düğümlemek', düşmek'ten düşlenmek 'Fazlaca meşgul olmak', kürümek’ten kürülenmek 'sürüklenmek', çalkamak'tan çalkalamak 'sallamak ve iyice sallamak' örneklerini verir (1991: 113-114). Kıpçak Türkçesinde de ekin aynı görevde kullanıldığını belirten Hacıeminoğlu, ekle ilgili; "Aslında isimlerden fiil yapan -la-/-le- bazı şivelerde fiil tabanlarından da pekiştirilmiş fiiller teşkil etmektedir. ”der (1991, s. 90).

Hacıeminoğlu'nun -lA- ekinin -AlA- ekine bağlanamayacağını savunan görüşünden hareketle Dönmez'in; (Kâmûs-ı Türkî̀'ye Göre) Türkçede Fiilden Fiil Yapan Ekler ve Kullanılışları adlı yüksek lisans tezine değinmek önem arz etmektedir. Çünkü söz konusu tezde Dönmez, ekin nereden geldiği ile ilgili bilgiler vererek ek üzerine dilcilerin görüşleri hakkında da ayrıntılar sunar. Daha sonra sunulan tüm bilgilerden hareketle; eki işlek olmayan fiilden fiil yapım ekleri arasında değerlendirir. Hatta bu bağlamda ekin pekiştirilmiş gövdeler yapmaya yarayan ekler arasında pek çok gramer kitabında da fiilden fiil yapma görevinde ele alınmadığını vurgular. Ekin -(A)1A- ekinden geldiği üzerine görüşlerin de bulunduğundan söz eden Dönmez, tüm bu bilgilerin sonucunda eki fiilden fiil yapma ekleri başlı̆̆ıyla değerlendirmeye alır (2012, s. 105). Dönmez'in, ekin fiilden fiil yapmaya yaradığını ispatlayan örneklerinden bazıları; abanmak'tan abanlamak 'büyük adım atmak, adımları fazlaca açmak', avrımak'tan avrılamak 'yayı kıvırmak', bağdamak'tan bağdalamak 'güreşte rakibin bacağını kendi bacağıyla sarıp alta düşürmek', yansımak'tan yansılamak 'yan yürümek, çarpık yürümek, taklit etmek, ses ya da 1şık geri dönmesi' şeklindedir.

Ayrıca A. Fehmi Karamanlıŏlu'nun Kıpçak Türkçesi Grameri adlı çalışmasında ekle ilgili (fiilden fiil yapma görevinde) şu örneklere yer verdiği görülmektedir; ayırmak'tan ayırlamak 'ayırmak, ayrılmak', buyurmak'tan buyurlamak 'kabul etmek', çızmak'tan çılaş̧mak 'yazmak, yazışmak', kayırmak'tan kayırlamak 'kayırmak, iltifat etmek', otamak'tan otalamak 'ilaç yapmak, iyileştirmek' (1994, s. 51).

Ekin, Eski Anadolu Türkçesi döneminde de bazı örneklerde açıkça kullanıldığı görülür. Daha önce de verdiğimiz ve Dede Korkut kitabında karşılaştığımız dügmek eserde 'düğümlemek ve bağlamak' anlamlarında karşımıza çıkar (Özçelik, 2016, s. 838). Paçacioğlu'nun Sözlüğü'nde yer alan ve Eski Anadolu Türkçesi eserlerinden olan Marzubanname'de çiğnemek anlamına gelen kebmekten keblemek 'gevelemek' olarak verilen 
eylem de yine fiilden fiil yapma görevini üstlenen bir örnek olarak karşımıza çıkmaktadır (2016, s. 358-359).

\section{2. Çağdaş Türk Yazı Dillerinde -lA- Eki}

Özbek Türkçesi -1A- ekini fiilden fiil yapım eki görevinde sıklıkla kullanır. "Asıl fiil anlamını pekişstirici, tekerrür ettirici işlevi vardır. İşlektir. Sesteş isim ve fiil tabanlarında kullanımında isimden fiil yapma eki gibi de düşünülebilecek olan bu ekin doğrudan fiil tabanlarına getirildiği örnekler az değildir: tongmak'tan tonglamak 'donmak, buz tutmak', bükmek'ten büklemek 'bükmek, kıvırmak', bulgämak'tan bulgälämak 'bulamak, batırtmak' (Öztürk, 2007, s. 308). Özellikle alıntılanan ibaredeki işlektir ifadesi ekin bu lehçede azımsanmayacak derecede kullanıldığını göstermesi bakımından dikkate değerdir.

Yeni Uygur Türkçesinde -1A- eki fiilin anlamını pekiştiren ve bu bağlamda yeni fiiller türeten eklerden olup şu örneklerde görülür: bolcamak'tan bolcalamak 'fal açmak', pükmek'ten püklämek 'bükmek', çoqmak'tan çoqulamak 'gagalamak' (Öztürk, 2007, s. 375; Öztürk, 2015, s. 48). Yeni Uygur Türkçesi Grameri’nde 'kesmek, parçalamak' anlamında keslemek örneğini veren Paçacioğlu bunun kesmekten geldiğini belirten örneği de gösterir (2016, s. 370-371).

Tamir, Kazak Türkçesinde kullanılan -lA- ile ilgili "fiilin gösterdiği hareketin tekrar tekrar yapıldığını gösterir" diyerek sabamak 'vurmak' sabalamak 'tekrar tekrar vurmak, dövmeye devam etmek', tistemek '1sırmak' ve tistelemek 'tekrar tekrar 1sırmak' örneklerini verir (2007, s. 449). Görüldüğü üzere; ekin Türkçenin hemen her döneminde fiilden fiil yapım eki bağlamında kullanıldığı örneklerle tespit edilmiştir.

\subsection{Türkiye Türkçesinde -IA- Eki}

Ekin Türkiye Türkçesinde de kullanıldığına dair örnekler mevcuttur. Bu örnekler; gözetmek'ten gözetlemek, salmak'tan sallamak, atmak'tan atlamak olarak siralanabilir. Aynı şekilde burada dermek'ten derlemek örneği de verilebilir. Çünkü Eski Türkçede ve Orta Türkçede tirmek ve tèrmek olarak 'derlemek, toplamak' (Gülensoy, 2011, s. 278-279) anlamına gelen fiil bugün de aynı anlamda ve biçimde karşımıza çıkmaktadır.

\subsection{Türkiye Türkçesi Ağızlarında -lA- Eki}

Dîvânu Lugât-it-Türk'te 'söylemek' anlamına gelen aymak fiilinin Türkiye Türkçesi ağızlarında 'sözü uzatmak' anlamında aylamak biçiminin yer aldığı görülmektedir (DS, 2009, s. 424). Yine Türkiye Türkçesi ağızlarında artmak'ın 'dövmek ve tokat atmak' anlamlarına geldiği görülmektedir (https://sozluk.gov.tr/, E.T. 12.11.2019). Eylem, Dîvânu Lugât-it-Türk’te artlamak biçiminde aynı anlamda kullanılmaktadır (Atalay, 1999, s. 38).

$$
\text { Tablo1. -1A- Eki }
$$

\begin{tabular}{|c|c|c|c|c|}
\hline Kelime & Anlam & Kelime & Anlam & Dönem \\
\hline aban- & büyük adım atmak & abanla- & $\begin{array}{l}\text { büyük adım atmak, } \\
\text { adımları fazlaca } \\
\text { açmak' }\end{array}$ & $\begin{array}{l}\text { Osmanlı } \\
\text { Türkçesi }\end{array}$ \\
\hline art- & $\begin{array}{l}\text { dövmek ve tokat } \\
\text { atmak }\end{array}$ & artla- & $\begin{array}{l}\text { dövmek ve tokat } \\
\text { atmak' }\end{array}$ & $\begin{array}{l}\text { Türkiye } \\
\text { Türkçesi } \\
\text { A ğıları }\end{array}$ \\
\hline at- & atmak & atla- & atlamak & $\begin{array}{l}\text { Türkiye } \\
\text { Türkçesi }\end{array}$ \\
\hline avr1- & yayı kıvırmak & avrila- & yayı kıvırmak & $\begin{array}{l}\text { Osmanlı } \\
\text { Türkçesi }\end{array}$ \\
\hline ay- & söylemek & ayla- & sözü uzatmak & $\begin{array}{l}\text { Türkiye } \\
\text { Türkçesi } \\
\text { A ğıları }\end{array}$ \\
\hline ay1r- & ayırmak & ayırla- & ayırmak & Kıpçak Türkçesi \\
\hline bağda- & güreşte & bağdala- & güreşte & Osmanl1 \\
\hline
\end{tabular}




\begin{tabular}{|c|c|c|c|c|}
\hline & $\begin{array}{l}\text { bacağını kendi } \\
\text { bacağıyla sarıp alta } \\
\text { düşürmek }\end{array}$ & & $\begin{array}{l}\text { bacağını } \\
\text { bacağıyla } \\
\text { düșürmek }\end{array}$ & Türkçesi \\
\hline bolca- & fal açmak & bolcala- & fal açmak & $\begin{array}{ll}\text { Yeni } & \text { Uygur } \\
\text { Türkçesi } & \end{array}$ \\
\hline bulga- & bulamak & bulgala- & bulamak & Özbek Türkçesi \\
\hline buyur- & buyurmak & buyurla- & $\begin{array}{ll}\begin{array}{l}\text { kabul } \\
\text { (buyruğu) }\end{array} & \text { etmek, }\end{array}$ & Kıpçak Türkçesi \\
\hline bük- & bükmek & bükle- & bükmek & Özbek Türkçesi \\
\hline çalka- & sallamak & çalkala- & iyice sallamak & 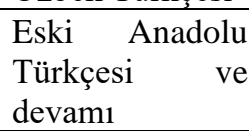 \\
\hline çız- & yazmak, yazışmak & çızla- & yazmak, yazışmak & Kıpçak Türkçesi \\
\hline çoğ- & $\begin{array}{l}\text { sarmak, } \\
\text { bağlamak }\end{array}$ & çoğla- & bohçalamak & $\begin{array}{l}\text { Karahanlı } \\
\text { Türkçesi }\end{array}$ \\
\hline çoqu- & gagalamak & çoqula- & gagalamak & $\begin{array}{ll}\text { Yeni } & \text { Uygur } \\
\text { Türkçesi } & \\
\end{array}$ \\
\hline düğg- & düğmelemek & düğle- & düğümle- & $\begin{array}{l}\text { Eski Anadolu } \\
\text { Türkçesi, } \\
\text { Osmanlı } \\
\text { Türkçesi, } \\
\text { Türkiye } \\
\text { Türkçesi }\end{array}$ \\
\hline düş- & meşgul olmak & düşle- & $\begin{array}{l}\text { fazlaca meşgul } \\
\text { olmak }\end{array}$ & $\begin{array}{l}\text { Eski Anadolu } \\
\text { Türkçesi }\end{array}$ \\
\hline gözet- & gözetmek & gözetle- & izlemek, gözetlemek & $\begin{array}{l}\text { Türkiye } \\
\text { Türkçesi }\end{array}$ \\
\hline 1rga- & iki yana sallamak & 1rgala- & iki yana sallamak & $\begin{array}{l}\text { Eski Anadolu- } \\
\text { Türkiye } \\
\text { Türkçesi }\end{array}$ \\
\hline ka- & sandiğa koymak & kala- & sandiğa koymak & $\begin{array}{l}\text { Karahanlı } \\
\text { Türkçesi }\end{array}$ \\
\hline kayır- & kayırmak & kayırla- & kayırmak & Kıpçak Türkçesi \\
\hline keb- & gevelemek & keble- & gevelemek & $\begin{array}{l}\text { Eski Anadolu } \\
\text { Türkçesi }\end{array}$ \\
\hline kolu- & ant içmek & kolula- & ant içmek & $\begin{array}{ll}\text { Eski } & \text { Uygur } \\
\text { Türkçesi } & \\
\end{array}$ \\
\hline kun- & çalmak & kunla- & $\begin{array}{l}\text { sürekli çalmak, } \\
\text { yağmalamak }\end{array}$ & Orhun Türkçesi \\
\hline kürü- & sürüklenmek & kürüle- & sürüklenmek & $\begin{array}{l}\text { Çağatay } \\
\text { Türkçesi, } \\
\text { Anadolu } \\
\text { Türkçesi } \\
\text { devamı }\end{array}$ \\
\hline ota- & ilaç yapmak & otala- & $\begin{array}{l}\text { ilaç yapmak, tedavi } \\
\text { etmek }\end{array}$ & Kıpçak Türkçesi \\
\hline pük- & bükmek & pükle- & bükmek & $\begin{array}{ll}\text { Yeni } & \text { Uygur } \\
\text { Türkçesi } & \\
\end{array}$ \\
\hline saba- & vurmak & sabala- & tekrar vurmak & Kazak Türkçesi \\
\hline sal- & etrafa yaymak & salla- & sağa sola sallamak & $\begin{array}{l}\text { Türkiye } \\
\text { Türkçesi }\end{array}$ \\
\hline tir-/tér- & $\begin{array}{l}\text { derlemek, } \\
\text { toparlamak }\end{array}$ & derle- & $\begin{array}{l}\text { derlemek, } \\
\text { toparlamak }\end{array}$ & $\begin{array}{l}\text { Eski Türkçe - } \\
\text { Türkiye } \\
\text { Türkçesi }\end{array}$ \\
\hline tın- & dinlenmek & tınla- & tinlenmek & $\begin{array}{ll}\text { Eski Uygur } \\
\text { Türkçesi, }\end{array}$ \\
\hline
\end{tabular}




\begin{tabular}{|c|c|c|c|c|}
\hline & & & & $\begin{array}{l}\text { Karahanlı } \\
\text { Türkçesi }\end{array}$ \\
\hline tiste- & 1sirmak & tistele- & tekrar Isırmak & Kazak Türkçesi \\
\hline tok1-/toku- & $\begin{array}{l}\text { vurmak, dövmek, } \\
\text { tokmaklamak }\end{array}$ & tokula- & $\begin{array}{l}\text { ham ipliği tokaçla } \\
\text { dövmek }\end{array}$ & $\begin{array}{l}\text { Eski Türkçe - } \\
\text { Türkiye } \\
\text { Türkçesi } \\
\text { Ağıları }\end{array}$ \\
\hline ton- & donmak & tonla- & donmak & Özbek Türkçesi \\
\hline yarut- & parlamak & yarutla- & parıldamak & $\begin{array}{ll}\text { Eski } & \text { Uygur } \\
\text { Türkçesi } & \\
\end{array}$ \\
\hline yans1- & $\begin{array}{lr}\text { yan yürümek, } \\
\text { çarpık yürümek, } \\
\text { taklit etmek, } & \text { ses ya } \\
\text { da } 1 \text { şı } & \text { geri } \\
\text { dönmesi } & \end{array}$ & yansila- & $\begin{array}{l}\text { yan yürümek, çarpık } \\
\text { yürümek, taklit } \\
\text { etmek, ses ya da 1şık } \\
\text { geri dönmesi }\end{array}$ & $\begin{array}{l}\text { Osmanl1 } \\
\text { Türkçesi }\end{array}$ \\
\hline
\end{tabular}

\section{Sonuç ve Öneriler}

Türk dilinin önemli bir alanını oluşturan eklerin, bilinen görevleri dışında farklı görevleri de olabileceği göz ardı edilmekte ya da olduğu ve bilindiği şekliyle kabul edilmektedir. Bugün bazı ekler üzerine yapılan birtakım çalışmalar bu eklerin bilinen görevlerinden başka kullanım alanlarının da olduğunu göstermektedir. Oysa herhangi bir ekin hangi görevde ve nasıl işlediğini bilmek için o ekle ilgili titiz bir çalışma yürütmek gerekebilir. Örneğin bir ekle ilgili yeni ya da farklı bir şeyler söyleyebilmek için ekin tarihsel metinlerde taranarak karşılaştırma yöntemiyle iyice ele alınması/araştırılması gerekmektedir. Canlı bir varlık olan dilin mutlak doğruları yoktur. Çünkü gelişir ve değişir; bu sebeple, özellikle yapı bağlamında bilinen ve mutlak doğru olarak kabul gören pek çok bilgi belki de bugün farklı kapıları aralayarak Türk dilini daha da zengin hale getirecektir.

Çalışmada Türkçenin bilinen en eski yazılı metinlerinden günümüze kadar pek çok örnekte isimden fiil yapma ekleri başlı̆g 1 altında değerlendirilen -lA- ekinin fiilden fiil yapma özelliğinin de olabileceği üzerinde durulmuştur. $\mathrm{Bu}$ bağlamda ekin, fiilden fiil yapma özelliğinin olup olmadığı konusunda örnekler verilerek tartışmaya sunulmuştur.

Elde edilen veriler dikkate alındığında ekin, Türkçenin dönemleri içerisinde kullanımında farklılıklar gösterdiği tespit edilmiştir. Öyle ki kimi zaman yoğun olarak fiilden fiil yapma eki olarak karşımıza çıkan ekin kimi zaman da sadece birkaç örnekle sınırlı kaldığı görülmüştür. Ancak çalışmanın geneli değerlendirildiğinde isimden fiil yapma eki olarak oldukça çok örneği bulunan -lA- ekinin, fiilden fiil yapma işleviyle de kullanıldığ görülmektedir. Bu sebeple ekin Türk dilbilgisi kaynak kitaplarında yeniden değerlendirilerek, isimden fiil yapım ekleri yanında, fiilden fiil yapım ekleri içerisinde de değerlendirilmesi uygun görülmektedir. Bu çalışma ile birlikte Türkçedeki diğer eklerin farklı işlevleri üzerine yapılacak çalışmalara zemin hazırlanmış olup yeni söylem ve tasniflendirmelere kapı aralanmış olacaktır.

\section{Kaynaklar}

Atalay, B. (1999). Divanü Lûgat-it-Türk Dizini, Ankara: TDK Yayınlar1.

Banguoğlu, T. (2015). Türkçenin Grameri, Ankara: TDK Yayınları.

Caferoğlu, A. (1968). Eski Uygur Türkçesi Sözlüğü. İstanbul: Edebiyat Fak. Matbaası.

Derleme Sözlüğü (2009). Ankara: TDK Yayınları,

De Saussure, F. (2001). Genel Dilbilim Dersleri (Çev: B. Vardar), İstanbul: Multilingual Yayınları. 
Dönmez, H. (2012). Kâmûs-ı Türkî’ye Göre Türkçede Fiilden Fiil Yapan Ekler ve Kullanılışları, Basılmamış Yüksek Lisans Tezi, İnönü Üniversitesi, Sosyal Bilimler Enstitüsü Yüksek Lisans Tezi, Malatya.

Eraslan, K. (2012). Eski Uygur Türkçesi Grameri, Ankara: TDK Yayınları.

Ercilasun, A. B., ; Akkoyunlu, Z. (2015). Kâşgarlı Mahmud Dîvânu Lugâti’t-Türk Giriş-MetinÇeviri-Notlar-Dizin. Ankara: TDK Yayınları.

Ergin, M. (2013). Edebiyat ve Eğitim Fakültelerinin Türk Dili ve Edebiyatı Bölümleri İçin Türk Dil Bilgisi, İstanbul: Bayrak Yayınc1lık.

Gabain A. V. (2007). Eski Türkçenin Grameri, (Çev: M. Akalın), Ankara: TDK Yayınları.

Gülensoy, T. (2011). Türkiye Türkçesindeki Türkçe Sözcüklerin Köken Bilgisi Sözlüğü, Ankara: TDK Yayınları.

Hacıeminoğlu, N. (1991). Türk Dilinde Yapı Bakımından Fiiller, Ankara: Kültür Bakanlığ Yayınları.

https://sozluk.gov.tr, Erişim Tarihi: 12.11.2019.

Johanson, L. (2014). Türkçe Dil Illişkilerinde Yapısal Etkenler, (Çev: N. Demir), Ankara: TDK Yayınlar1.

Karamanlıoğlu, A. F. (1994) Kıpçak Türkçesi Grameri, Ankara: TDK Yayınları

Kaya, C. (1994). Uygurca Altun Yaruk: Giriş, Metin ve Dizin, Ankara: TDK Yayınları

Korkmaz, Z. (2014). Türkiye Türkçesi Grameri Şekil Bilgisi, Ankara: TDK Yayınları.

Özçelik, S. (2016). Dede Korkut -Dresden Nüshast- Metin, Dizin, C.II., Ankara: TDK Yayınları.

Öztürk, R. (2007). Türk Lehçeleri Grameri, Özbek Türkçesi (Ed: A. B. Ercilasun), Ankara: Akçağ Yayınları.

Öztürk, R. (2015). Yeni Uygur Türkçesi Grameri, Ankara: TDK Yayınları.

Paçacıŏglu, B. (2016). VIII.-XVI. yüzyıllar arasında Türkçenin sözcük dă̆arcı̆̆ı, İstanbul: Kesit Yayınları.

Tamir, F. (2007). Türk Lehçeleri Grameri, Kazak Türkçesi, (Ed: A. B. Ercilasun), Ankara: Akçağ Yayınları.

Tekin, Ş. (1976). Maytrısimit: Burkancıların Mehdîsi Maitreya ile Buluşma Uygurca İptidaî Bir Dram: Burkancılı̆̆ın Vaibhāșika Tarikatine Âit: Bir Eserin Uygurcası (No. 54). Ankara: Sevinç Matbaası.

Tekin, T. (2016). Orhon Türkçesi Grameri, (Yay: M. Ölmez), İstanbul: Türk Dilleri Araştırmalar Dizisi.

Üşenmez, E. (2010). Karahanlı Türkçesi Sözlüğ̈̈, İstanbul: Doğu Kitabevi

Yazıcı Ersoy, H. (2007). Türk Lehçeleri Grameri, Yeni Uygur Türkçesi, (Ed: A. B. Ercilasun), Ankara: Akçağ Yayınları.

\section{ETIKK VE BİLIMSEL İLKELER SORUMLULUK BEYANI}

$\mathrm{Bu}$ çalışmanın tüm hazırlanma süreçlerinde etik kurallara ve bilimsel atıf gösterme ilkelerine riayet edildiğini yazarlar beyan eder. Aksi bir durumun tespiti halinde Afyon Kocatepe Üniversitesi Sosyal Bilimler Dergisi'nin hiçbir sorumluluğu olmayıp, tüm sorumluluk makale yazarlarına aittir. 